\title{
Modification of the Cardiovascular
}

\section{Effects of L-Dopa by Decarboxylase Inhibitors}

\author{
August M. Watanabe, Leon C. Parks, and Irwin J. Kopin with the \\ technical assistance of VIRGINIA K. WEISE
}

From the Laboratory of Clinical Science, National Institute of Mental Health, Bethesda, Maryland 20014

A в S T R A C T Intravenously infused L-dopa $(0.3 \mathrm{mg} /$ $\mathrm{kg}$ per min) produced hypertension and cardiac arrhythmias in halothane anesthetized dogs. Biochemical studies showed that the heart, kidney, and brain of these animals accumulated significant amounts of catecholamines formed from the administered precursor.

Pretreatment of dogs with an extracerebral inhibitor of dopa decarboxylase [D,L- $\alpha$-hydrazino- $\alpha$-methyl- $\beta-(3,4-$ dihydroxyphenyl) propionic acid] prevented the development of hypertension and arrhythmias with infusion of L-dopa. Instead, these animals developed significant hypotension. The heart and kidney of these animals accumulated markedly reduced amounts of catecholamines formed from L-dopa compared with dogs receiving L-dopa alone; the amount of catecholamines accumulated in brain was unchanged. L-dopa, after extracerebral decarboxylase inhibition, appeared to produce hypotension by reducing peripheral vascular resistance without altering sympathetic nerve function. During hypotension, cardiac output was not altered and arterial pressure in perfused hindlimbs fell, even though flow was maintained. The pressor response to intravenous injections of norepinephrine and dopamine was unchanged. Hindlimb arterial pressure response to direct electrical stimulation of the lumbar sympathetic trunk was also unchanged.

Pretreatment with a drug which inhibits brain as well as extracerebral dopa decarboxylase [D,L-seryl-2,3,4-trihydroxybenzylhydrazine hydrochloride] abolished all effects of L-dopa on blood pressure. In these animals, there was a marked reduction of catecholamine formation from L-dopa in the brain as well as the heart and kidney.

Received for publication 4 August 1970 and in revised form 1 February 1971.
It appears that L-dopa produces opposite effects on blood pressure depending on the site of accumulation of its metabolic products, dopamine and norepinephrine. If L-dopa is rapidly decarboxylated to catecholamines in peripheral organs, hypertension and cardiac arrhythmias occur. If peripheral dopa decarboxylase is selectively inhibited, a centrally mediated hypotensive effect, probably secondary to the accumulation of catecholamines in the brain, becomes apparent. If dopa decarboxylase is inhibited in the brain in addition to extracerebral organs, L-dopa has no effect on blood pressure.

\section{INTRODUCTION}

As treatment of Parkinson's syndrome with L-dopa has become more prevalent, cardiovascular side effects have been observed with increasing frequency. Hypertension and cardiac arrhythmias, effects which may reflect the presence of excessive amounts of catecholamines, have been observed in some patients receiving L-dopa (1-3). Much more common, however, has been the development of hypotension in patients receiving this therapy $(1,2$, 4). The mechanism by which L-dopa may produce hypertension in some patients and a paradoxical depressor effect in other patients is unclear.

The present study was performed to directly examine some cardiovascular effects of L-dopa in anesthetized dogs. We have given L-dopa alone as well as after pretreatment with decarboxylase inhibitors, and we have attempted to correlate the rate of formation of catecholamines in heart, kidney, and brain with the effects of L-dopa on blood pressure. The rate of decarboxylation of L-dopa was altered by administration of an inhibitor of decarboxylase which does not readily penetrate the bloodbrain barrier, MK 485 [D,L- $\alpha$-hydrazino- $\alpha$-methyl- $\beta$ - $(3,4-$ 
dihydroxyphenyl) propionic acid] ${ }^{1}$ (5), and one which has been reported to be an effective inhibitor of both peripheral and brain decarboxylase, RO 4-4602 [D,Lseryl-2,3,4-trihydroxybenzylhydrazine hydrochloride] (5). In dogs made hypotensive with L-dopa, we have also examined certain hemodynamic parameters and evaluated the function of sympathetic nerves.

\section{METHODS}

Blood pressure studies. Mongrel dogs weighing 18-25 $\mathrm{kg}$ were anesthetized with sodium thiamylal, $50 \mathrm{mg} / \mathrm{kg}$ intravenously and connected via a cuffed endotracheal tube to an anesthesia machine (Heidbrink Kinetometer, Ohio Medical Products, Madison, Wis.) through which a halothane$\mathrm{O}_{2}$ mixture was administered for maintenance anesthesia. Tidal volume and respiratory rate were controlled to maintain arterial $\mathrm{pH}$ between 7.3 and 7.5 throughout the experiment. Halothane was administered in a concentration of 1.75-2.0\%. Esophageal temperature was monitored and maintained at a constant level with a thermal blanket (Aquamatic-K-Thermia, Gorman-Rupp Industries, Inc., Bellville, Ohio). Foreleg veins were cannulated for administration of drugs. Arterial blood pressure was measured with a Statham P23DB transducer (Statham Instruments Inc., Oxnard, Calif.) connected to an arterial cannula. Pressure and electrocardiogram were recorded on a multichannel direct writing recorder (Sanborn Division, Hewlett-Packard Co., Waltham, Mass.).

L-dopa ${ }^{2}$ was dissolved in physiological saline, adjusted to $\mathrm{pH} 2.0$ with hydrochloric acid, and delivered at a constant rate through a continuous infusion pump (Harvard Apparatus Co, Millis, Mass.). Blood pressure responses to varying doses of L-dopa were determined by administering doses, in random sequence, ranging between 0.0001 and 0.3 $\mathrm{mg} / \mathrm{kg}$ per min. If a pressor effect was observed, the blood pressure was allowed to return to baseline levels before another dose was given. In all other experiments L-dopa was administered at a rate of $0.3 \mathrm{mg} / \mathrm{kg}$ per min. MK $485^{3}$ $(50 \mathrm{mg} / \mathrm{kg}$ administered intravenously over a $15 \mathrm{~min}$ interval) or RO $4-4602^{4}(100 \mathrm{mg} / \mathrm{kg}$ administered intravenously over a $45 \mathrm{~min}$ interval) were given at the times indicated in Results.

Other cardiovascular studies. In all these experiments, dogs were pretreated with $\mathrm{MK} 485(50 \mathrm{mg} / \mathrm{kg})$ and given I.-dopa at a rate of $0.3 \mathrm{mg} / \mathrm{kg}$ per min. Changes in peripheral resistance in an isolated vascular bed were studied by perfusing the left hindlimb with blood obtained from the aorta and pumped through a peristaltic pump (Sigmamotor Inc, Middleport, N. Y.) into a cannula placed in the left external iliac artery. To eliminate significant collateral flow, the aorta below the origin of the internal iliac arteries, the inferior mesenteric artery, and three pairs of lower lumbar arteries were ligated. The peristaltic pump was calibrated to deliver blood to the hindlimb at rates ranging from 34 to $260 \mathrm{ml} / \mathrm{min}$. The left lumbar sympathetic trunk

${ }^{1}$ Abbreviations used in this paper: MK 485, D,L- $\alpha$-hydrazino- $\alpha$-methyl- $\beta$-(3,4-dihydroxyphenyl) propionic acid; RO 4-4602, D,L-seryl-2,3,4,-trihydroxybenzylhydrazine hydrochloride.

${ }^{2}$ Purchased from Nutritional Biochemicals Corp., Cleveland, Ohio.

${ }^{3}$ Supplied by Merck Sharp \& Dohme Co., West Point, Pa.

${ }^{4}$ Supplied by Hoffmann-La Roche Inc., Nutley, N. J. and both carotid arteries were isolated and bilateral cervical vagotomy was performed. The effects of administration of norepinephrine (1.0 $\mu \mathrm{g} / \mathrm{kg}$, base) intravenously, dopamine $(100 \mu \mathrm{g} / \mathrm{kg}$, base) (intravenously), bilateral carotid occlusion, and direct electrical stimulation of the sympathetic nerves on hindlimb perfusion pressure were measured before and after drug administration. The left sympathetic trunk was stimulated at the level of $\mathrm{L}_{3}$ to $\mathrm{L}_{4}$ with bipolar platinum electrodes at a frequency ranging between 1 and 30 cycles/sec, an impulse duration of $0.5 \mathrm{msec}$, and supramaximal voltage $(20 \mathrm{v})$.

Cardiac output was measured with an electromagnetic flow probe (Biotronex Lab, Inc, Silver Spring, Md.) placed on the main pulmonary artery and recorded on a flow-meter.

Biochemical studies. In these experiments, tritiated Ldopa $^{5}$ was mixed with unlabeled L-dopa so that the final specific activity was 2.5 or $5.0 \mu \mathrm{Ci} / \mathrm{mg}$ and infused at a rate of $0.3 \mathrm{mg} / \mathrm{kg}$ per min for $30 \mathrm{~min}$. At the end of the infusion of labeled L-dopa, the brain, heart, and kidney were removed and immediately frozen on dry ice. After thawing, the tissues were homogenized in 4 volumes of $0.4 \mathrm{~N}$ perchloric acid and a portion of the homogenate centrifuged ai $10,000 \times g$ for $30 \mathrm{~min}$. A portion of the clear supernatant fluid was assayed for labeled catecholamines (dopamine and norepinephrine) using sequential alumina adsorption and Dowex 50 ion exchange and elution as previously described (6).

Statistical significance of differences between means was evaluated by $t$ tests ( 7 ).

\section{RESULTS}

Effect of L-dopa on the arterial blood pressure of anesthetized dogs. Intravenous infusion of $\mathrm{L}$-dopa at rates of $0.0001-0.1 \mathrm{mg} / \mathrm{kg}$ per $\min$ for $30 \mathrm{~min}$ did not alter significantly the mean arterial blood pressure of anesthetized dogs (Fig. 1, each point represents mean $\pm \mathrm{SE}$ of the mean [ $\mathrm{ISEM}]$ of three dogs). When 0.2 or

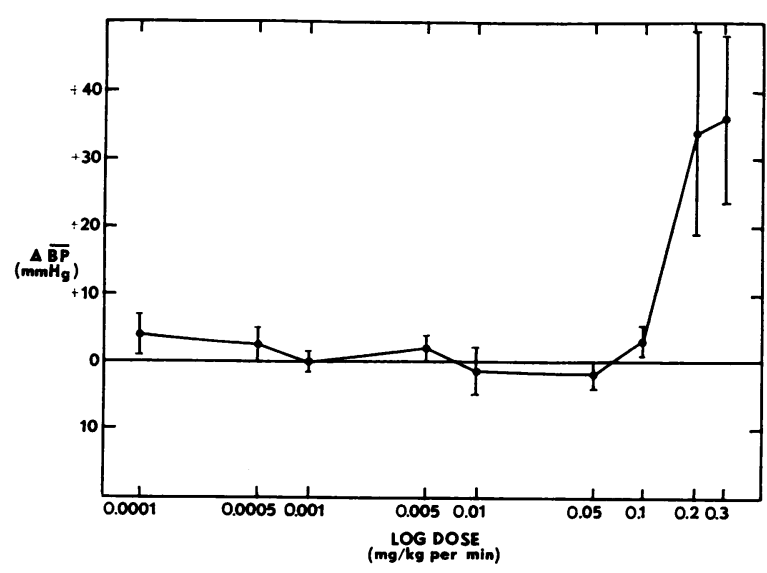

Figure 1 Log dose-response curve. Changes in mean arterial blood pressure represent the difference between baseline pressure and pressure after $30 \mathrm{~min}$ of L-dopa infusion. Points are mean $\left( \pm_{\mathrm{SEM}}\right)$ of three animals.

\footnotetext{
${ }^{5}$ Purchased from New England Nuclear, Boston, Mass.
} 


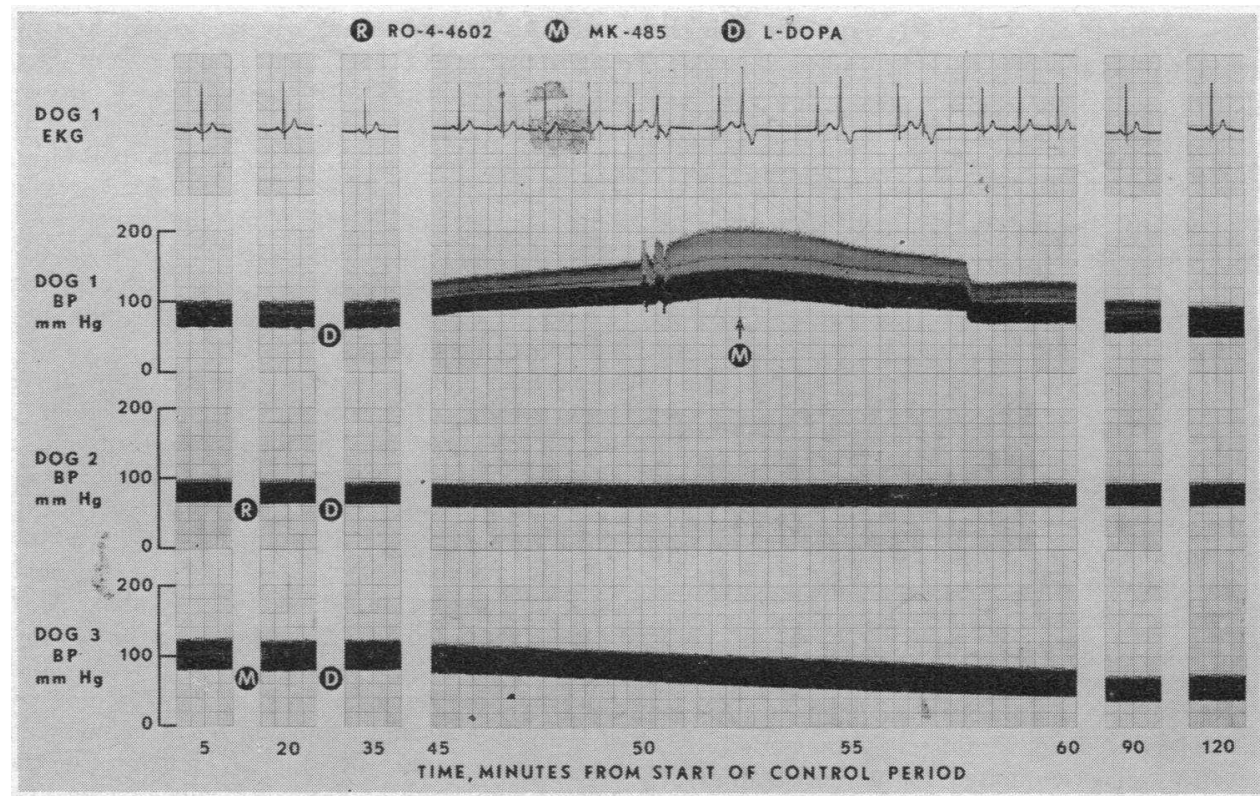

FIgURE 2 Typical recordings of blocd pressure changes with L-dopa infusion. MK 485 (M) and RO 4-4602 (R) were administered at the times shown. L-dopa $(0.3 \mathrm{mg} / \mathrm{kg}$ per min) was continuously infused from " $D$ " to end of tracings. Paper speed of the pressure recordings was $0.25 \mathrm{~mm} / \mathrm{sec}$. EKG illustrates representative rhythms of $\operatorname{dog} 1$ and does not correlate in time with the blood pressure tracing.

$0.3 \mathrm{mg} / \mathrm{kg}$ per min was infused, blood pressure increased markedly (Fig. 1; dog 1, Fig. 2). After 45 min of infusion of L-dopa at a rate of $0.3 \mathrm{mg} / \mathrm{kg}$ per min, the mean rise in blood pressure of nine dogs was $43.3 \pm 4.7 \mathrm{~mm}$ Hg (Fig. 3). All dogs developed cardiac arrhythmias which began with premature ventricular systoles, developed into ventricular bigeminy (dog 1, Fig. 2), and in some dogs, progressed to ventricular tachycardia or ventricular fibrillation. After $45 \mathrm{~min}$ of infusion, the administration of L-dopa was terminated, the dog had died, or MK $485(50 \mathrm{mg} / \mathrm{kg}$ ) was rapidly administered intravenously. In two dogs in which L-dopa infusion could be continued for $105 \mathrm{~min}$, blood pressures remained elevated and their means are plotted in Fig. 3.

Effect of decarboxylase inhibition on L-dopa induced arterial hypertension. MK $485(50 \mathrm{mg} / \mathrm{kg})$ and $\mathrm{RO}$ 4-4602 (100 mg/ $\mathrm{kg})$ were each administered alone to four dogs. These drugs had no effect on blood pressure for periods up to four $\mathrm{hr}$ after administration. MK 485 pretreatment abolished the hypertension and arrhythmias produced by L-dopa (dog 3, Fig. 2). Instead, nine dogs treated with MK 485 followed by the infusion of L-dopa at a rate of $0.3 \mathrm{mg} / \mathrm{kg}$ per min, developed hypotension with a mean fall in pressure of $33.8 \pm 5.2 \mathrm{~mm} \mathrm{Hg} 75$ min after start of infusion (Fig. 3).

In some animals, which had developed arrhythmias during infusion of L-dopa (these animals had not been pretreated with a decarboxylase inhibitor), a single bolus of intravenously administered MK 485 rapidly abolished the arrhythmia and reversed the hypertensive effect (dog 1, Fig. 2).

Pretreatment with RO 4-4602 also abolished the hypertension and arrhythmias induced by L-dopa. Seven dogs pretreated with RO 4-4602 did not develop hypotension during $2 \mathrm{hr}$ of L-dopa infusion at a rate of 0.3 $\mathrm{mg} / \mathrm{kg}$ per min (dog 2, Fig. 2; Fig. 3).

Effect of MK 485 followed by L-dopa infusion on peripheral resistance and cardiac output. The pressure

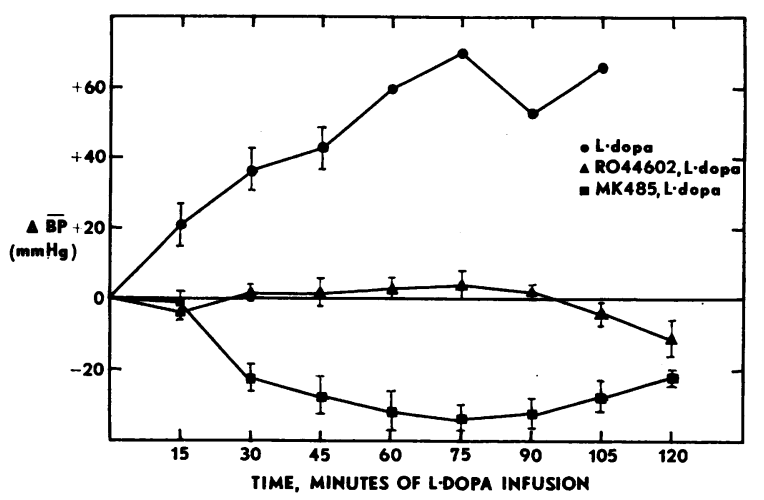

FigURE 3 Summary of mean arterial blood pressure changes with L-dopa infusion at a rate of $0.3 \mathrm{mg} / \mathrm{kg}$ per min. Points are mean $( \pm \mathrm{SEM})$ of nine dogs in the L-dopa group up to $45 \mathrm{~min}$ and two dogs beyond $45 \mathrm{~min}$, seven dogs in the group pretreated with $\mathrm{RO} 4-4602$, and nine dogs pretreated with MK 485. 
in the artery of the perfused hindlimb was directly related to the rate of blood flow to the limb (Fig. 4, each point represents mean \pm SEM of four dogs). After treatment with MK 485 and infusion of L-dopa at a rate of $0.3 \mathrm{mg} / \mathrm{kg}$ per min, there was a significant decrease, at several flow rates, in hindlimb perfusion pressure (Fig. 4). This apparent decrease in peripheral resistance paralleled the decrease in systemic blood pressure. Cardiac output in five dogs was not significantly changed by MK 485 followed by L-dopa infusion for $1 \mathrm{hr}$, although blood pressure in these animals fell markedly (Fig. 5).

Effect of MK 485 followed by L-dopa infusion on sympathetic neuronal function. In six dogs, the central aortic and hindlimb perfusion pressure responses to the injection of norepinephrine was not significantly changed by MK 485 followed by infusion of L-dopa at a rate of $0.3 \mathrm{mg} / \mathrm{kg}$ per min for about $1 \mathrm{hr}$ (Fig. 6). Likewise, the pressor response in the aorta and hindlimb to the injection of dopamine was unchanged in three dogs (Fig. 7). The increase in hindlimb perfusion pressure in response to direct electrical stimulation of the lumbar sympathetic nerve was also unchanged by MK 485 followed by $1 \mathrm{hr}$ of L-dopa infusion in three dogs (Fig. 8). In all these experiments, the mean arterial pressure was significantly lowered by the combination treatment of MK 485 and L-dopa.

In seven dogs, the increase in aortic pressure with bilateral carotid occlusion was $39.7 \pm 8.5 \mathrm{~mm} \mathrm{Hg}$ before L-dopa treatment and $18.6 \pm 9.8 \mathrm{~mm} \mathrm{Hg}(P<0.001)$ after $1 \mathrm{hr}$ of L-dopa infusion in MK 485 pretreated dogs. After L-dopa treatment, the mean arterial pressure in most of these dogs was about $60 \mathrm{~mm} \mathrm{Hg}$ compared to a baseline value of about $95 \mathrm{~mm} \mathrm{Hg}$. Prochnik, Maison,

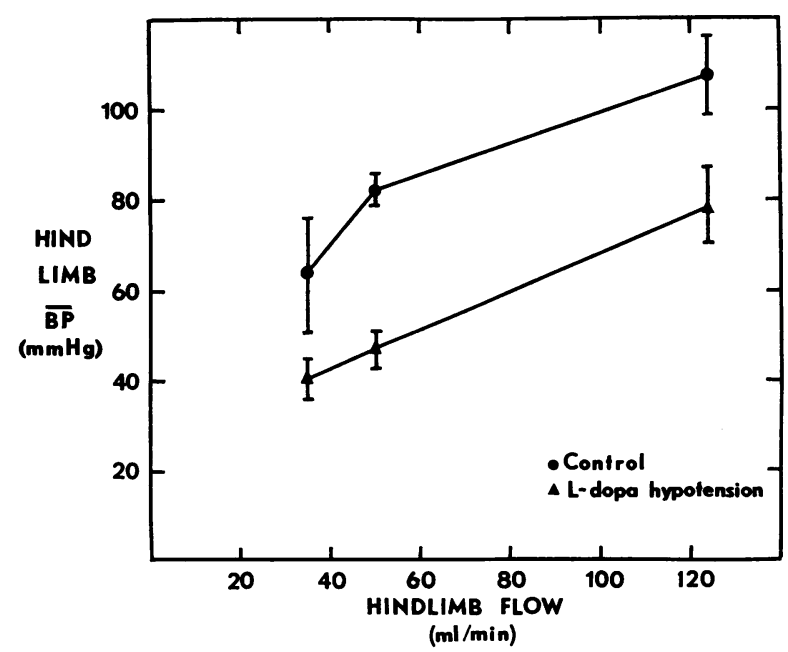

FigURE 4 Relationship of hindlimb perfusion pressure to rate of hindlimb blood flow. Points represent mean ( \pm SEM) of four animals during a control period and after production of hypotension with L-dopa in MK 485 pretreated dogs.

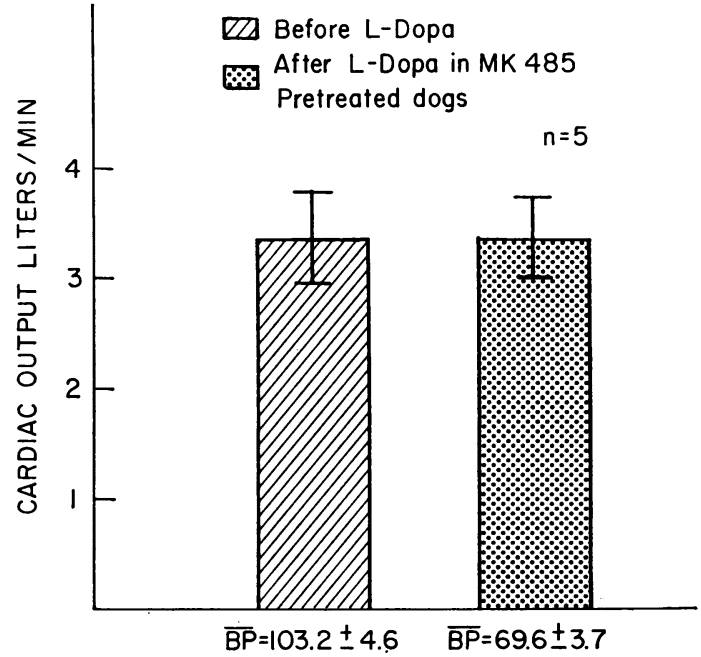

Figure 5 Cardiac output, expressed in liters per minute, in five dogs before treatment and after $1 \mathrm{hr}$ of infusion of L-dopa $(0.3 \mathrm{mg} / \mathrm{kg}$ per $\mathrm{min})$ after $\mathrm{MK} 485$ pretreatment. Values shown are mean $\pm_{\text {SEM. }}$. Mean blood pressures at the time cardiac output was measured are noted below the bars.

and Stutzman demonstrated that the pressor response to bilateral carotid occlusion is directly related to the mean blood pressure existing when the reflex is evoked (8). Analysis of our data according to a formula suggested by him, revealed that the reduction in baroreceptor response that we observed could be entirely due to the pronounced hypotension produced in these animals.

Effect of decarboxylase inhibitors on formation of catecholamines from $\mathrm{L}-d o p a-H^{s}$. In six dogs which had received L-dopa $(0.3 \mathrm{mg} / \mathrm{kg}$ per $\mathrm{min})$ labeled with tritiated L-dopa $(2.5$ or $5.0 \mu \mathrm{Ci} / \mathrm{mg})$ there was the expected elevation of blood pressure at the end of $30 \mathrm{~min}$ of infusion. At this time, the hearts, kidneys, and brains of these animals had accumulated significant amounts of catecholamines which had been formed from the tritiated precursor (Table I). Six dogs pretreated with MK 485 had a marked reduction in levels of tritiated catecholamines in the hearts and kidneys, but no significant change in the brains. These animals had a decrease in blood pressure. In six dogs pretreated with RO 4-4602 there was a significant decrease in tritiated catecholamine content in the brains as well as the hearts and kidneys. No change in blood pressure was apparent in animals pretreated with $\mathrm{RO} 4-4602$.

\section{DISCUSSION}

Infusion of L-dopa in doses up to $0.1 \mathrm{mg} / \mathrm{kg}$ per $\min$ produced no change in blood pressure of anesthetized dogs. When 0.2 or $0.3 \mathrm{mg} / \mathrm{kg}$ per min L-dopa was infused, there was a significant elevation of blood pressure and development of cardiac arrhythmias. The biochemi- 


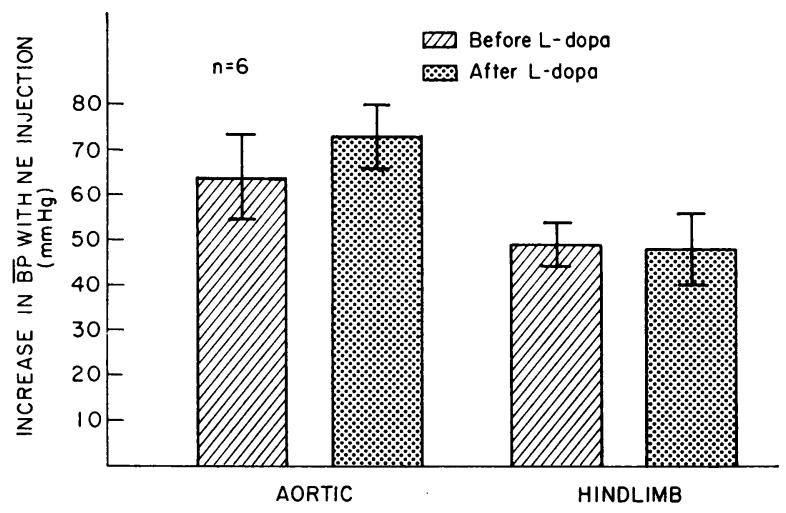

FIGURE 6 Increase in aortic and hindlimb perfusion mean blood pressures in response to injection of norepinephrine (NE). This was performed before treatment and after 1 $\mathrm{hr}$ of infusion of L-dopa $(0.3 \mathrm{mg} / \mathrm{kg} \cdot \operatorname{per} \mathrm{min})$ in $\mathrm{MK} 485$ pretreated dogs. Values are mean \pm SEM of six dogs.

cal studies showed that significant amounts of catecholamines formed from L-dopa had accumulated in extracerebral organs. The development of hypertension was probably a consequence of the formation of catecholamines (dopamine and norepinephrine) by decarboxylation of L-dopa. Dopamine stimulates beta-adrenergic receptors of the myocardium (9) and beta or alpha adrenergic receptors of the vascular beds of dogs (10). With large enough doses of dopamine, stimulation of alpha receptors predominates and peripheral vascular resistance is increased. This combined with increased cardiac output produces a pressor response (11). The cardiovascular effects of norepinephrine are well-known (12). The arrhythmias observed were probably also secondary to the accumulation of catecholamines in the heart in the presence of halothane anesthesia. Haloge-

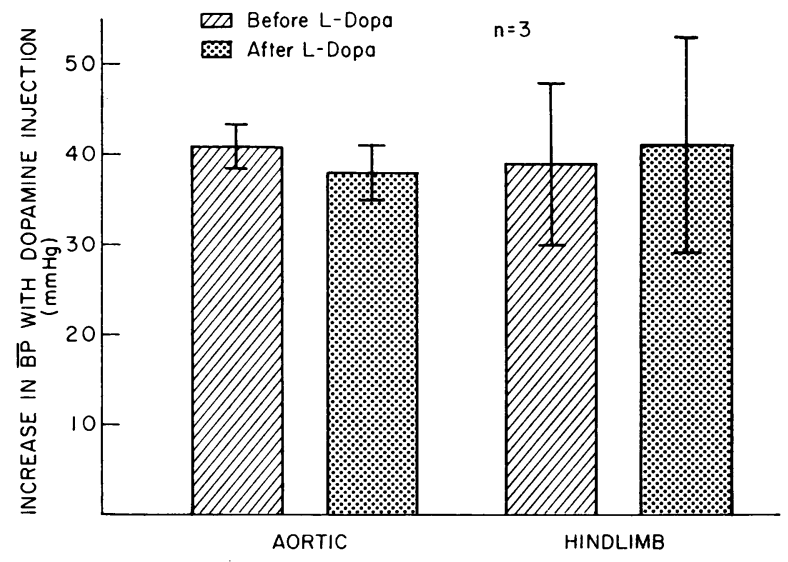

Figure 7 Increase in aortic and hindlimb perfusion mean blood pressures in response to injection of dopamine. Measurements were obtained before treatment and after $1 \mathrm{hr}$ of infusion of L-dopa $(0.3 \mathrm{mg} / \mathrm{kg}$ per $\mathrm{min})$ in $\mathrm{MK} 485$ pretreated animals. Values are mean $\pm_{\mathrm{SEM}}$ of three dogs. nated hydrocarbons are known to potentiate the arrhythmogenic effects of catecholamines (13).

Pretreatment with MK 485 markedly reduced catecholamine formation from tritium-labeled L-dopa in the heart and kidney, but not in brain. This was expected since this drug does not readily penetrate the bloodbrain barrier (5). The block in decarboxylation of L-dopa in extracerebral organs appeared to prevent the development of hypertension and hypotension became apparent. The peripheral decarboxylase inhibitor was also effective in preventing or reversing the arrhythmias which developed during infusion of L-dopa.

The cardiac output and hindlimb perfusion studies demonstrated that the hypotension caused by L-dopa after MK 485 pretreatment was secondary to a reduction in peripheral resistance of vascular beds. Pressure in the perfused hindlimb fell even though flow was maintained and cardiac output was unchanged by this treatment. This reduction in peripheral resistance was not associated with any change in adrenergic nerve or receptor function. The blood pressure response to intravenous norepinephrine, dopamine, or nerve stimulation was not altered.

Low doses of dopamine lower blood pressure in anesthetized dogs by selectively dilating certain vascular

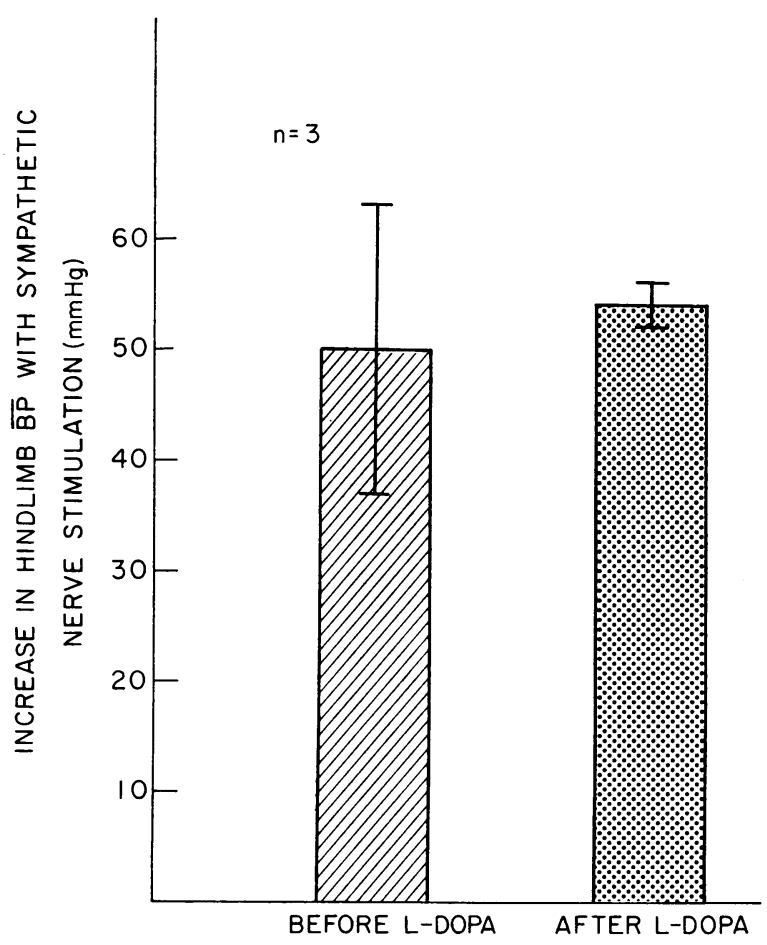

Figure 8 Increase in hindlimb perfusion pressure in response to direct electrical stimulation of the lumbar sympathetic trunk before treatment and after $1 \mathrm{hr}$ of L-dopa infusion $(0.3 \mathrm{mg} / \mathrm{kg}$ per $\mathrm{min})$ in $\mathrm{MK} 485$ pretreated dogs. Values are mean \pm SEM of three dogs. 
beds (10). It appears unlikely that this is the mechanism by which L-dopa produces hypotension in MK 485 pretreated dogs, since infusion of low doses of L-dopa (which presumably would mimic incomplete inhibition of decarboxylation of L-dopa) did not have this effect, and RO 4-4602, which also inhibited the decarboxylation of L-dopa, did not produce hypotension although it prevented the development of hypertension.

The similarity of levels of catecholamines accumulated in the brain of dogs receiving L-dopa alone and those receiving L-dopa after MK 485 was surprising. With more L-dopa available to brain, because of extracerebral decarboxylase inhibition, it was thought that higher levels of catecholamines would accumulate in brain, as has been reported with other animals (14). There are two possible explanations for this. In anesthetized dogs $M K$ 485 may, in the dose used, enter brain and partially inhibit decarboxylase. Also, in the assay procedure, the whole brain was homogenized. Major vessels such as the vertebral and carotid branches and the circle of Willis were removed but arterioles and capillaries were homogenized with the parenchyma. Flourescent histochemical studies have shown that when L-dopa is ad-

TABLE I

Catecholamine Formation from Tritiated L-Dopa in Dog Heart, Kidney, and Brain*

\begin{tabular}{|c|c|c|c|c|}
\hline \multirow[b]{2}{*}{ Treatment } & \multirow{2}{*}{$\begin{array}{c}\text { Dog } \\
\text { number }\end{array}$} & \multicolumn{3}{|c|}{ Tritiated catecholamines $\ddagger$} \\
\hline & & Heart & Kidney & Brain \\
\hline \multirow[t]{6}{*}{ Control } & $2-43$ & 246 & 869 & 67 \\
\hline & $2-56$ & 311 & 282 & 96 \\
\hline & $1-78$ & 248 & 3390 & 94 \\
\hline & $1-45$ & 156 & 1036 & 103 \\
\hline & $1-55$ & 157 & 1420 & 90 \\
\hline & $1-38$ & 143 & 1380 & 102 \\
\hline Mean \pm SEM & & $210.2 \pm 27.8$ & $1396.2 \pm 433.0$ & $92.0 \pm 5.4$ \\
\hline \multirow[t]{6}{*}{ MK 485} & $2-45$ & 15 & 20 & 113 \\
\hline & $2-35$ & 15 & 83 & 63 \\
\hline & 5-99 & 16 & 14 & 66 \\
\hline & $5-67$ & 18 & 18 & 92 \\
\hline & 4-38 & 15 & 16 & 61 \\
\hline & $3-60$ & 32 & 32 & 117 \\
\hline Mean \pm SEM & & $18.5 \pm 2.7 \S$ & $30.5 \pm 10.8 \S$ & $85.3 \pm 10.5$ \\
\hline \multirow[t]{6}{*}{ RO 4-4602 } & $5-78$ & 29 & 277 & 24 \\
\hline & $5-52$ & 22 & 68 & 34 \\
\hline & $4-76$ & 13 & 15 & 52 \\
\hline & $5-82$ & 24 & 33 & 49 \\
\hline & 4-72 & 22 & 22 & 42 \\
\hline & $5-83$ & 32 & 23 & 51 \\
\hline Mean \pm SEM & & $23.7 \pm 2.7 \S$ & $73.0 \pm 41.5 \S$ & $42.0 \pm 4.5 \| \rrbracket$ \\
\hline
\end{tabular}

* Tritiated L-dopa ( 2.5 or $5.0 \mu \mathrm{Ci} / \mathrm{mg}$ ) was infused at a rate of $0.3 \mathrm{mg} / \mathrm{kg}$ per min for $30 \mathrm{~min}$. At the end of infusion animals were killed and tissues analyzed for catecholamines as described in text.

$\ddagger$ Results expressed as counts per minute present in the tissues divided by the total radioactive dose of $\mathrm{L}$-dopa (in $\mu \mathrm{Ci}$ ) administered to the dog.

$\& P<0.001$ compared to control.

$\| P<0.01$ compared to control.

I $P<0.01$ compared to $\mathrm{MK} 485$. ministered to rats, dopamine accumulates in capillaries of the brain (15). When L-dopa is administered with a decarboxylase inhibitor, the accumulation of dopamine is mainly in the brain parenchyma (15). Thus the level of catecholamines seen in the dogs receiving L-dopa after MK 485 may represent higher parenchymal levels than dogs receiving L-dopa alone, whose dopamine may have accumulated primarily in capillary walls.

While MK 485 appears to be a poor inhibitor of brain decarboxylase (5), RO 4-4602, in large doses, penetrates into brain of rats where it effectively inhibits decarboxylase (5). In dogs, in a dose of $100 \mathrm{mg} / \mathrm{kg}$, it also appears to inhibit significantly formation of catecholamines from L-dopa in brain. The inhibition of decarboxylation of L-dopa in brain and peripheral organs produced by RO $4-4602$, completely abolished changes in blood pressure.

Intravenous L-dopa thus appears to produce opposing effects on blood pressure in anesthetized dogs depending on the site of accumulation of its metabolic products, dopamine and norepinephrine. Hypertension and arrhythmia occur when L-dopa is decarboxylated in extracerebral tissues. During rapid formation of catecholamines in the periphery, this effect predominates. Hypotension is dependent on conversion of L-dopa to catecholamines in brain; this effect becomes apparent after inhibition of peripheral decarboxylase. Hypotension is produced without altering the function of sympathetic nerves or receptors. The accumulation of catecholamines in certain areas of brain may reduce central sympathetic outflow, thereby causing a dilatation of peripheral arterioles and reducing blood pressure.

These findings are in agreement with those of Henning and Rubenson who recently showed that intraperitoneally administered L-dopa produces hypertension in conscious normotensive rats (16). This hypertensive effect could be abolished by pretreatment with MK 485 . A larger dose of L-dopa after MK 485 pretreatment causes a significant lowering of blood pressure (16). It has also been shown that concentrations of norepinephrine in lower brainstem and hypothalamus of genetically hypertensive rats is lower than in control rats (17). Administration of L-dopa with MK 485, which may increase the levels of norepinephrine in these areas of brain, appears to lower the blood pressure of these rats (17).

In another recently published study, Whitsett, $\mathrm{Ha}$ lushka, and Goldberg showed that L-dopa impairs the function of postganglionic sympathetic nerves in dogs (18). This produces an attenuation of the carotid-occlusion baroreceptor reflex and the rise in femoral vascular resistance in response to sympathetic nerve stimulation. This action of L-dopa appears to be dependent on decarboxylation of L-dopa in peripheral tissues, as RO 4-4602 in a dose of $50 \mathrm{mg} / \mathrm{kg}$ abolishes this effect (18). A decarboxylated product of L-dopa thus appears to pro- 
duce a direct inhibitory effect on sympathetic nerves in dogs. This peripheral effect many contribute to the hypotensive action of L-dopa. The results of the present study would suggest, however, that the hypotensive action of L-dopa is not dependent on this peripheral effect of its decarboxylated product. Hypotension occurred when peripheral decarboxylase was inhibited and while adrenergic neuronal function was not impaired.

The findings of the present study may provide some insight into the mechanism by which L-dopa produces cardiovascular effects in patients. Some patients may be either more sensitive to catecholamines or, because of differences in metabolism of administered L-dopa, accumulate catecholamines in extracerebral tissues. These patients may therefore develop hypertension or cardiac arrhythmias when treated with large doses of L-dopa. More commonly, cardiovascular effects suggesting the presence of excessive amounts of peripheral catecholamines are not apparent. Rather, patients became hypotensive. Hypotension is especially marked in the standing position but recumbent blood pressure also appears to be lowered $(4,19)$. Furthermore, inhibition of extracerebral decarboxylase appears to potentiate the hypotensive effect of L-dopa (19). In these patients, hypotension may be secondary to the accumulation of catecholamines in the central nervous system.

\section{REFERENCES}

1. Yahr, M. D., R. C. Duvoisin, M. J. Schear, R. E. Barrett, and M. M. Hoehn. 1969. Treatment of parkinsonism with levodopa. Arch. Neurol. 21: 343.

2. McDowell, F., J. E. Lee, T. Swift, R. D. Sweet, J. S. Ogsbury, and J. T. Kessler. 1970. Treatment of Parkinson's syndrome with levodopa. Ann. Intern. Med. 72: 29.

3. Cotzias, G. C., P. S. Papavasiliou, and R. Gellene. 1969. Modification of parkinsonism-chronic treatment with L-dopa. N. Engl. J. Med. 280: 337.

4. Calne, D. B., J. Brennan, A. S. D. Spiers, and G. M. Stern. 1970. Hypotension caused by L-dopa. Brit. Med. J. 1: 474.

5. Bartholini, G., and A. Pletscher. 1969. Effect of various decarboxylase inhibitors on the cerebral metabolism of dihydroxyphenylalanine. J. Pharm. Pharmacol. 21: 323.

6. Musacchio, J. M., J. E. Fischer, and I. J. Kopin. 1966. Subcellular distribution and release by sympathetic nerve stimulation of dopamine and $\alpha$-methyl dopamine. J. Pharmacol. Exp. Ther. 152: 51.

7. Dixon, W. F., and F. J. Massey, Jr. 1969. In Introduction to Statistical Analysis. McGraw-Hill Book Co., New York. 3rd edition. 109.

8. Prochnik, G., G. L. Maison, and J. W. Stutzman. 1950. Carotid-occlusion-pressor reflex: influence of existing mean arterial pressure, of anesthetics and of ganglionic and adrenergic blocking drugs. Amer. J. Physiol. 162: 553.

9. Black, W. L., and E. L. Rolett. 1966. Dopamine-induced alterations in left ventricular performance. Circ. Res. 19: 71.

10. Eble, J. N. 1964. A proposed mechanism for the depressor effect of dopamine in the anesthetized dog. $J$. Pharmacol. Exp. Ther. 145: 64.

11. McDonald, R. H., and L. I. Goldberg. 1963. Analysis of the cardiovascular effects of dopamine in the dog. J. Pharmacol. Exp. Ther. 140: 60.

12. Goodman, L. S., and A. Gilman. 1970. In The Pharmacological Basis of Therapeutics. The Macmillan Co., New York. 4th edition. 497.

13. Katz, R. L., and G. J. Katz. 1966. Surgical infiltration of pressor drugs and their interaction with volatile anesthetics. Brit. J. Anaesth. 38: 712.

14. Lotti, V. J., and C. C. Porter. 1970. Potentiation and inhibition of some central actions of L-dopa by decarboxylate inhibitors. J. Pharmacol. Exp. Ther. 172: 406.

15. Constantinidis, J., G. Bartholini, R. Tissot, and A. Pletscher. 1968. Accumulation of dopamine in the parenchyma after decarboxylase inhibition in the capillaries of brain. Experientia (Basel). 24: 130.

16. Henning, M., and A. Rubenson. 1970. Central hypotensive effect of L-3,4-dihydroxyphenylalanine in the rat. $J$. Pharm. Pharmacol. 22: 553.

17. Yamori, Y., W. Lovenberg, and A. Sjoerdsma. 1970. Norepinephrine metabolism in brainstem of spontaneously hypertensive rats. Science (Washington). 170: 544.

18. Whitsett, T. L., P. V. Halushka, and L. I. Goldberg. 1970. Attenuation of postganglionic sympathetic nerve activity by L-dopa. Circ. Res. 27: 561 .

19. Watanabe, A. M., T. N. Chase, and P. V. Cardon. 1970 Effect of L-dopa alone and in combination with an extracerebral decarboxylase inhibitor on blood pressure and some cardiovascular reflexes. Clin. Pharmacol. Ther. 11: 740 . 